\title{
Leitura/escrita de crianças: comparações entre grupos de diferentes escolas públicas ${ }^{1}$
}

\author{
Jerusa Fumagalli de Salles ${ }^{2}$ \\ Maria Alice de Mattos Pimenta Parente \\ Lia Beatriz de Lucca Freitas \\ Universidade Federal do Rio Grande do Sul, Porto Alegre-RS, Brasil
}

\begin{abstract}
Resumo: A fim de traçar perfis e comparar o desempenho de leitura/escrita de 110 crianças de $2^{\text {a }}$ série de cinco escolas públicas, foram avaliadas leitura e escrita de palavras/pseudopalavras isoladas e compreensão de leitura textual. Na análise de cluster, identificaram-se três subgrupos: desempenho elevado em leitura/escrita (86,36\%); desempenho baixo em leitura/ escrita $(10 \%)$ e desempenho muito baixo em leitura/escrita (3,64\%). Um total de 15 crianças (13,64\% da amostra) apresentou alguma dificuldade de leitura e escrita de palavras. As diferenças de desempenho não foram estatisticamente significativas para a leitura de palavras, mas na escrita o desempenho das crianças da escola 3 foi significativamente superior ao das crianças das escolas 1,2 e 5. Mesmo sendo todas escolas públicas, que atendiam a uma população predominantemente de classe média-baixa, houve variabilidade de desempenhos em leitura e escrita, mais expressiva na escrita e na compreensão de leitura textual.
\end{abstract}

Palavras-chave: leitura, escrita, escolas, compreensão, linguagem escrita.

\section{Children's reading/writing: comparison among groups of different public schools}

\begin{abstract}
Aiming to define the profile and compare the reading/writing performance of $1102^{\text {nd }}$ grade children from five public schools, their reading and writing of isolated words/pseudowords and reading comprehension were evaluated. Through cluster analysis, three sub-groups were identified: high $(86.36 \%)$ reading/writing performance; low (10\%) reading/writing performance; and very low (3.64\%) reading/writing performance. A total of 15 children (13.64\% of the total sample) displayed some difficulty in reading and writing words. The differences in performance were not statistically significant for word reading, though the written performance of children from School 3 was significantly better than that of children from the Schools 1, 2 and 5. Even though all the studied schools were public schools in areas where the low-middle social class predominate, variable reading and writing performance was observed, more expressive in writing and reading comprehension.
\end{abstract}

Keywords: Reading, writing, schools, comprehension, written language.

\section{Lectura/escrita de niños: comparación entre grupos de diferentes escuelas públicas}

Resumen: Con el fin de trazar perfiles y comparar el rendimiento de la lectura/escrita de 110 alumnos de $2^{\circ}$ año de cinco esuelas públicas, fueron evaluadas la lectura y la escrita de palabras/pseudopalabras aisladas y la comprensión de la lectura de texto. En el análisis de cluster se identificaron tres subgrupos: alto rendimiento en lectura /escrita (86,36\%); bajo rendimiento en lectura/escrita (10\%) y muy bajo rendimiento en lectura/escrita (3,64\%). Un total de 15 alumnos (13,64\% de la muestra) mostró alguna dificultad de lectura y escrita de palabras. Las diferencias de rendimiento no fueron estadísticamente significativas en la lectura de palabras, sin embargo en la escrita el rendimiento de los alumnos de la escuela 3 fue significativamente superior al de los niños de las escuelas 1, 2 y 5 . Hubo variabilidad en la muestra del rendimiento en lectura y escrita, siendo más expresiva en la escrita y en la comprensión de la lectura de texto.

Palabras clave: lectura, escrita, escuelas, comprensión, lenguaje escrita.

O desenvolvimento, assim como as alterações, das habilidades de leitura e escrita em crianças estão relacionados a uma série de fatores da criança, da família, da escola, do sistema educacional, entre outros (Sternberg \& Grigorenko, 2003). Portanto, o sucesso ou fracasso no processo de ensinoaprendizagem da leitura/escrita sofre a influência de fatores biológicos, neuropsicológicos, psicossociais (dos contextos familiar e escolar) e pedagógicos. A predisposição para a

\footnotetext{
${ }^{1}$ Este texto foi revisado segundo Acordo Ortográfico da Língua Portuguesa (1990), em vigor a partir de $1^{\circ}$ de janeiro de 2009.

${ }^{2}$ Endereço para correspondência:

Jerusa Fumagalli de Salles. Av. Ramiro Barcelos, 2600, sala 114. Instituto de Psicologia-UFRGS. Porto Alegre-RS. CEP: 90.035-003. E-mail: jerusafs@yahoo.com.br / website: www.ufrgs.br/neuropsicologia
}

dislexia, por exemplo, depende de condições biológicas em interação com o ambiente (Frith, 1997). O envolvimento desses múltiplos fatores pode explicar a variabilidade individual encontrada na alfabetização, inclusive em crianças frequentando a mesma classe de uma mesma série/ano escolar.

Adicionalmente, os processos cognitivo-linguísticos envolvidos na leitura e na escrita são distintos, podendo ter um curso de desenvolvimento também diferente em uma mesma criança, com variações entre crianças. No sistema de escrita do português brasileiro há poucas irregularidades para a leitura, mas muitas palavras cuja grafia correta depende da internalização de regras ou do uso de estratégias puramente lexicais de escrita (acionar o conhecimento prévio). Desta forma, há de se esperar que o aprendizado destas habilidades tenha exigências de ensino distintas e que se encontrem diferenças de desempenho entre as habilidades de leitura e de 
escrita. Há uma variabilidade na aprendizagem e no uso das estratégias de leitura e de escrita, tanto em crianças competentes, quanto naquelas que apresentam dificuldades nesse aprendizado (Pinheiro, 2001; Salles \& Parente, 2006a). Sousa e Maluf (2005) investigaram a relação entre as habilidades de leitura e escrita em 73 crianças brasileiras no início da escolarização e encontraram que as crianças em níveis mais avançados da alfabetização ( $2^{\mathrm{a}}$ serie) têm maior habilidade na leitura do que na escrita. Quando as crianças começam a utilizar estratégias ortográficas/lexicais (utilização do conhecimento prévio) de leitura e de escrita, elas passam a ler melhor do que escrevem.

Salles e Parente (2007a) verificaram que as crianças de $2^{\mathrm{a}}$ série de escolas públicas usam ambas as rotas de leitura e de escrita de palavras isoladas, mas preferencialmente a fonológica, considerando os modelos de leitura e escrita de dupla-rota (Coltheart, Rastle, Perry, Langdon, \& Ziegler, 2001; Ellis \& Young, 1988). Esta estratégia fonológica trará poucas consequências à precisão de leitura, já que a criança pode se auto-corrigir, por exemplo, ao perceber que a leitura "táchi" não está correta, inferindo que "deve ser" táxi, então. Na escrita, estas inferências tornam-se muito mais difíceis, já que é uma atividade de produção, sem pistas.

Dentre os fatores psicossociais relacionados à aprendizagem escolar estão os conceitos de autoeficácia, motivação para aprender, crenças (Medeiros, Loureiro, Linhares, \& Marturano, 2000, 2003), aspectos afetivos (Loureiro, Marturano, Linhares, Machado, \& Silva, 1994), fatores da escola, ambiente de aprendizagem, tipo e intensidade da instrução, características do professor e recursos no ambiente familiar, como capacidade de lidar com os desafios da integração à escola, envolvimento parental com a escolarização do filho, presença de recursos no ambiente físico, práticas educativas e disciplina (Marturano, 1999). Ainda, variáveis socioeconômicas (Leybaert, Alégria, Deltour \& Skinkel, 1997; Pennington, 1997; Yavas \& Haase, 1988), ambiente sociocultural (Witter, 1996) e variáveis sociolinguísticas (Tasca, 2002), como nível de escolaridade, classe socioeconômica e instrução específica sobre regras de escrita, estão relacionadas ao desempenho das crianças em leitura e escrita.

$\mathrm{O}$ fator escola, entendido como qualidade dos professores e/ou métodos de ensino, tem impacto nas habilidades de leitura e escrita de crianças de séries iniciais de escolarização (Leybaert e cols., 1997). Especialmente nas escolas públicas brasileiras, o professor precisa estar preparado para lidar com a diversidade de ambientes socioculturais e de conhecimentos de base das crianças (Carvalho, 2000). Aliado a isso, salienta-se o desconhecimento de muitos professores em relação ao processo de aquisição da leitura e escrita (Freitas, 1989; Kleiman, 2001; Tasca, 1990). Para Kleiman (2001), os professores são mal informados sobre o processo de leitura, o leitor e as estratégias que levam ao seu domínio, o que impede que eles assumam o ensino de leitura com segurança e coerência. Com isso, as abordagens de ensino são, muitas vezes, dissociadas da forma como a criança aprende.
Por outro lado, no estudo de Salles e Parente (2007b), a categorização geral, pelo professor, do desempenho em linguagem escrita dos alunos estava correlacionada positivamente (mas de forma moderada) com o desempenho das crianças nas tarefas de leitura e escrita.

Inserido no fator escola, Gardinal e Marturano (2007) mostram que os indicadores de qualidade das relações mantidas no contexto escolar também estão correlacionados aos escores de escrita e leitura. Nesse estudo, os comportamentos nos três domínios - relação com a tarefa, com os colegas e o professor - correlacionaram-se com medidas de desempenho em leitura e escrita. Desta forma, a qualidade das relações estabelecidas na escola de educação infantil pode afetar o aprendizado. Segundo essas autoras, crianças menos envolvidas nas atividades de sala de aula, mais dependentes e mais agressivas nos relacionamentos, mostram menor progresso acadêmico. Estas questões, acrescentam as autoras, estão muito relacionadas ao modo como o professor organiza as atividades, portanto, sendo passíveis de prevenção. Por outro lado, Oliveira e Wechsler (2002) observaram a pouca importância dada para a área da interação professor - aluno ao entrevistarem alunos de licenciatura e professores.

Parece haver uma crença de que escolas de Ensino Fundamental particulares são melhores do que as públicas $\mathrm{e}$, consequentemente, passa-se a crer que o desempenho das crianças que frequentam as escolas públicas é inferior e homogêneo comparado às que frequentam as escolas privadas, ou seja, todas as crianças teriam um desempenho mais fraco e semelhante entre si. Pesquisas comparando o desempenho neuropsicolinguístico de crianças/adolescentes de escolas públicas e privadas têm sido feitas no Brasil (DalVesco, Mattos, Benincá, \& Tarasconi, 1998; Ferreira e Dias, 2002; Malloy-Diniz e cols., 2008; Silva \& Spinillo, 1998) e em outros países, como Argentina (Nogueira e cols., 2005; Pagliuso \& Pasian, 2007). É importante salientar que a realidade da escola pública pode ser vista como bastante diversa da escola privada, sendo necessários mais estudos de comparação de alunos de escolas públicas entre si.

Comparando-se os estudos realizados por Salles e Parente (2002a), com crianças de escolas privadas, e Salles e Parente (2007a), em escolas públicas, que compartilharam o mesmo instrumento de avaliação da leitura de palavras/ pseudopalavras, foram encontrados resultados mais favoráveis em termos de precisão no reconhecimento de palavras no primeiro estudo. Este resultado está supostamente relacionado à variável tipo de escola (pública versus particular). Fatores culturais ou ambientais, como o acesso à escolarização (e qualidade desta), tendem a produzir diferenças nas mensurações de habilidades cognitivas (Coppens, Parente, \& Lecours, 1998), como a leitura e a escrita.

Face à carência de estudos com crianças que compartilham características socioeconômicas e culturais, ultrapassando a comparação escola pública-privada, o presente trabalho tem por objetivo verificar se existe homogeneidade no desempenho em tarefas de leitura e escrita entre crianças 
de escolas públicas de uma cidade do interior do Rio Grande do Sul, podendo ser considerada com uma espécie de estudo de caso, pois refere-se a um contexto específico sociodemográfico. $\mathrm{O}$ estudo pretende responder às seguintes questões: 1) considerando a leitura e a escrita de palavras, quais os subgrupos encontrados em crianças de segunda série? e 2) mesmo sendo todas provenientes de segundas séries de escolas públicas estaduais de uma mesma cidade de porte médio do Rio Grande do Sul, as crianças de cada escola diferirão significativamente em leitura e escrita? Para atingir tais objetivos foram realizados dois estudos: 1) análise de subgrupos (clusters) de crianças pelo desempenho em leitura e escrita e 2) análise comparativa do desempenho dos estudantes de cada uma das cinco escolas.

\section{Método}

\section{Participantes}

Participaram deste estudo 110 crianças de segunda série do Ensino Fundamental de cinco escolas da rede pública estadual de uma cidade do Rio Grande do Sul, com idades entre
7,6 e 14 anos $(M=8,5$ anos; $\mathrm{DP}=0,9)$, sendo 54 meninas $(49,1 \%)$ e 56 meninos $(50,9 \%)$. A amostra foi selecionada através do procedimento de amostragem por área geográfica. Uma escola pública estadual de cada uma das cinco áreas urbanas da cidade foi sorteada para participar da pesquisa. De cada uma das cinco escolas selecionadas, foi sorteada uma turma de alunos de segunda série para constituir a amostra. O critério de exclusão da amostra foi a não autorização pelos pais/responsáveis da criança à sua participação na pesquisa.

Entende-se que os agrupamentos denominados nesse trabalho "fator escola" compreendem também um conjunto de variáveis sociodemográficas que se agrupam ao se considerar cada "escola" separadamente. Entre essas variáveis encontram-se: a) a característica da professora e de sua interação com as crianças, b) a região geográfica, c) grupo sócio-cultural de determinada região, d) o perfil da turma quanto aos seus aspectos sócio-culturais, interesses e desenvolvimento escolar que interferem no desempenho de cada criança do grupo. A distribuição da amostra, por escola, juntamente com as médias de idade dos alunos e de alguns dados dos professores de cada uma das cinco turmas avaliadas, encontra-se na Tabela 1.

Tabela 1

Distribuição do número e das médias (desvio-padrão - DP) de idade (em anos) das crianças, além de dados das professoras (idade, tempo de atuação na docência e escolaridade), por escola

\begin{tabular}{|c|c|c|c|c|c|}
\hline \multirow{2}{*}{ Escolas } & \multicolumn{2}{|c|}{$\begin{array}{c}\text { Crianças } \\
\mathbf{N}=110\end{array}$} & \multicolumn{3}{|c|}{$\begin{array}{c}\text { Professoras } \\
\mathrm{N}=5\end{array}$} \\
\hline & $\mathbf{N}$ & $\begin{array}{l}\text { Média idade } \\
\quad \pm \text { DP }\end{array}$ & $\begin{array}{l}\text { Idade } \\
\text { (anos) }\end{array}$ & $\begin{array}{l}\text { Tempo de docência } \\
\text { (anos) }\end{array}$ & Escolaridade \\
\hline Escola 1 & 25 & $8,36 \pm 0,49$ & 27 & 3 & Ensino Superior \\
\hline Escola 2 & 22 & $8,5 \pm 0,49$ & 48 & 25 & Ensino Médio - Magistério \\
\hline Escola 3 & 21 & $8,36 \pm 0,49$ & 57 & 31 & Ensino Superior \\
\hline Escola 4 & 19 & $8,21 \pm 0,29$ & 45 & 25 & Ensino Superior \\
\hline Escola 5 & 23 & $8,98 \pm 1,42$ & 45 & 24 & Ensino Superior \\
\hline Total & 110 & $8,5 \pm 0,9$ & 44,4 & $44,4(10,89)$ & \\
\hline
\end{tabular}

Das crianças estudadas, $13(11,8 \%)$ repetiram uma série escolar ( $1^{\mathrm{a}}$ ou $2^{\mathrm{a}}$ série), oito $(7,2 \%)$ apresentavam dificuldade de fala (alterações fonológicas ou articulatórias). A amostra incluiu uma criança portadora de necessidades educativas especiais (dificuldades motoras), em regime de inclusão. A inclusão destas crianças na amostra é justificada pelo fato de um dos objetivos deste estudo ser o de investigar o desempenho e a variabilidade em linguagem escrita das crianças de segunda série de escolas públicas e nestas encontram-se crianças com tais dificuldades.

O corpo docente das escolas selecionadas, em sua maioria, é composto por profissionais com formação em magistério e nível superior (pedagogia, letras, geografia, entre outros). A média de idade das professoras foi de 44,4 anos $(\mathrm{dp}=10,89)$ e a média de tempo de atuação no magistério, de 21,6 anos $(\mathrm{dp}=10,76)$.

\section{Instrumentos}

Avaliação da leitura de palavras isoladas (Salles \& Parente, 2002a, 2002b, 2007a): avalia a precisão na leitura oral de palavras (e pseudopalavras) isoladas, que variam em suas características psicolinguísticas de regularidade (estímulos regulares e irregulares), lexicalidade (palavras reais e pseudopalavras), extensão (estímulos curtos e longos) e frequência de ocorrência na língua (palavras frequentes e não frequentes). $\mathrm{O}$ instrumento consistiu de 60 estímulos, sendo 20 de cada categoria (palavras regulares, irregulares e pseudopalavras). As palavras reais variam quanto à frequência, 
segundo a lista de frequência de ocorrência de palavras expostas a crianças na faixa de pré-escola e séries iniciais, desenvolvida por Pinheiro (1996). Foram consideradas palavras curtas, estímulos dissilábicos, constituídos por até cinco letras, e palavras longas, estímulos polissilábicos, contendo oito ou mais letras. Os estímulos foram apresentados aleatoriamente, de forma individual, em fichas, e os participantes foram orientados a lê-los em voz alta. Os resultados são expostos em termos de porcentagem de acertos no total da tarefa e em cada categoria de estímulos.

Avaliação da escrita de palavras isoladas: a tarefa consiste em 40 estímulos (30 palavras reais e dez pseudopalavras, por exemplo, "nefoxosa") que variam em suas características psicolinguísticas de lexicalidade (palavras reais e pseudopalavras), regularidade (palavras regulares, irregulares e regra) e extensão. Os estímulos curtos são dissilábicos de até cinco letras e os longos, trissilábicos e polissilábicos, contendo seis ou mais letras. Dentre as palavras reais, 16 são irregulares, seis são regulares e oito são do tipo regra, 18 são longas e 12 são curtas. Os escores são expostos em porcentagem de acertos em cada categoria de estímulos.

Avaliação da compreensão de leitura textual (Salles \& Parente, 2002b): a compreensão de leitura de texto foi avaliada através da resposta a questões de múltipla escolha sobre a história “A Coisa", adaptada do texto de Rocha (1997), com aproximadamente 200 palavras de extensão e níveis apropriados de legibilidade para o nível de escolaridade da amostra. A criança deveria ler silenciosamente a história e depois responder ao questionário, composto por 10 perguntas, cada uma delas acompanhada de quatro itens de múltipla escolha. Metade das questões propostas relacionava-se com memória para eventos e caracteres descritos na própria história e a outra metade avaliava a compreensão inferencial. O examinador lia oralmente para a criança as questões e as respectivas opções de resposta, enquanto a mesma podia acompanhar a leitura visualmente. Os resultados são apresentados em termos de médias de porcentagem de questões respondidas corretamente.

\section{Considerações éticas}

A pesquisa foi aprovada pelo Comitê de Ética em Pesquisa da Universidade Federal do Rio Grande do Sul (protocolo $\left.n^{\circ} 229\right)$. Os pais consentiram com a participação das crianças no estudo por meio da assinatura do Termo de Consentimento Livre e Esclarecido.

\section{Procedimentos}

\section{Coleta de dados}

As crianças autorizadas pelos pais a participar da pesquisa, foram avaliadas em uma sessão coletiva (escrita de palavras isoladas) e em uma sessão individual (leitura de palavras isoladas e compreensão de leitura textual).

\section{Análise dos dados}

A análise foi feita, inicialmente, com a amostra total $(\mathrm{n}=110)$, por meio de cluster hierárquico (Johnson \& Wichern, 1998), com a finalidade de identificar subgrupos quanto às rotas (estratégias) preferencialmente usadas na leitura e escrita de palavras isoladas e quanto à variabilidade de perfis na amostra (objetivo 1). Foram utilizadas porcentagem de acertos na tarefa de leitura de palavras regulares, irregulares e pseudopalavras e porcentagem de acertos na escrita de palavras regulares, irregulares, regra e pseudopalavras. Para comparação de médias do desempenho em leitura e escrita de palavras isoladas entre os subgrupos formados pela análise de cluster, foi aplicado o Teste de comparação de Médias entre grupos (OneWay Anova). Esta mesma análise foi utilizada para comparar o desempenho das crianças de cada uma das cinco escolas na leitura e na escrita de palavras e de texto (objetivo 2). A análise Post Hoc foi feita com o método Dunnett T3.

\section{Resultados}

As escolas atendiam alunos com nível socioeconômico e cultural médio e baixo. Estas ofereciam, em geral, ensino fundamental, médio e Educação de Jovens e Adultos (EJA). $\mathrm{O}$ critério de formação das turmas também era variado, sendo definido por idade, por dificuldades de escrita e leitura ou por escolha dos pais. As turmas comportavam entre $20 \mathrm{e}$ 25 alunos cada. A maioria das escolas participantes oferecia atividades extracurriculares, como aulas de dança, judô e informática, apoio pedagógico aos alunos que apresentavam alguma dificuldade, passeios externos e projetos artísticos. Os recursos físicos das escolas eram compostos dos seguintes itens: biblioteca, sala de vídeo, laboratório, sala de informática e auditório, além do espaço externo, que variava de tamanho de acordo com a instituição, para a realização de atividades extra-aula.

A concepção de educação adotada por essas instituições, segundo informações fornecidas pelos professores e diretores, girava em torno de uma visão humanista de educação, na qual o aluno é valorizado além de seu conhecimento cognitivo, e a busca de formação de indivíduos críticos e criativos, com condições de transformar e questionar a sociedade em que vivem (SIC). Ao serem questionados sobre a abordagem de ensino utilizada, os professores mencionaram termos como "modelos tradicionais de educação" e "construtivismo". Pode-se inferir que todas as escolas usavam uma abordagem mista no ensino da leitura e escrita, estimulando a relação oralidade-escrita, mas também trabalhando com unidades maiores, como a palavra, a frase e o texto. Alguns trechos das entrevistas que evidenciam estas questões:

Eu sempre dei tudo junto, normalmente eu tirava palavras do texto pra exercitar a leitura. Ela é vista 
mais como um todo. Eu vejo que tem dificuldade com $t, d, f, n, e, p, b$. Daí eu tento fazer um trabalho mais fonético, mas no geral eu trabalho as vogais individualmente. (...) Quando há troca na escrita eu aponto e peço pra ler de novo, pois quando eles relêem, geralmente se dão conta. A leitura, até na separação de sílaba, eles trocam, dai eu digo não existe esta palavra, por isso eles têm que separar corretamente como eles falam, pra ter compreensão da palavra (professora da Escola 1).

Eu digo que ele tem que prestar atenção, da mesma forma que ele pronuncia a frase ele vai ter que escrever corretamente (professora da Escola 3).

Tem toda aquela questão, eu vou trabalhar no todo, no contexto, ou eu vou trabalhar a relação somgrafema (...). O som é bem importante porque no momento que ele conseguir detectar o som ele já, automaticamente, ele vai conseguir ler mais (professora da Escola 4).

A maioria das escolas definiu-se como flexível em relação à metodologia, buscando que o aluno seja sujeito de seu próprio conhecimento e enfocando a construção de novas formas de educação por meio do diálogo ensino-aprendizagem. Em geral, as escolas não mostram muitas diferenças quanto ao nível de escolaridade dos professores, a infraestrutura e as concepções pedagógicas.

\section{Subgrupos de crianças quanto ao desempenho em leitura e escrita}

A análise descritiva do desempenho em leitura e escrita de palavras da amostra geral foi apresentada em Salles e Parente (2007a). O presente estudo pretendeu investigar a ocorrência de subgrupos de desempenho em linguagem escrita (estratégias preferencialmente usadas na leitura e escrita de palavras) nesta amostra, constituindo subperfis, através da análise de cluster, assim comparando o desempenho da amostra de cada escola. Conforme a configuração do dendograma da análise de cluster, foram identificados três subgrupos, caracterizados a seguir.

Grupo com desempenho elevado em leitura e escrita de palavras (grupo DE): composto por 95 crianças $(86,36 \%$ da amostra) que apresentaram desempenho acima da média geral da série no total das tarefas de leitura e escrita de palavras isoladas e em todas as categorias de estímulos - regulares, irregulares e pseudopalavras. Este grupo caracteriza-se por apresentar precisão no uso de ambas as rotas de leitura e escrita. Houve uma distribuição equilibrada de crianças de cada uma das escolas pesquisadas: $21,1 \%$ da escola $1 ; 17,9 \%$ da escola $2 ; 21,1 \%$ da escola $3 ; 18,9 \%$ da escola 4 e $21,5 \%$ da escola 5 .

Grupo com desempenho baixo em leitura e escrita de palavras (grupo DB): composto por onze crianças $(10 \%$ da amostra) que apresentaram desempenho inferior à média geral de porcentagem de acertos da amostra no total das tarefas de leitura e escrita de palavras isoladas e em todas as categorias de estímulos. Este grupo caracteriza-se por apresentar dificuldades no uso de ambas as rotas de leitura e escrita, principalmente no uso da rota lexical (desempenho em leitura e escrita de palavras irregulares inferior ao obtido na leitura e na escrita de pseudopalavras). A maior parte deste grupo era proveniente das escolas $1(n=5)$ e $2(n=3)$. Apenas uma criança de cada uma das demais escolas $(9,1 \%$ de cada escola) integrava este grupo.

Grupo com desempenho muito baixo em leitura e escrita de palavras (grupo DMB): composto por quatro crianças que apresentaram desempenho muito baixo no total da leitura e escrita de palavras isoladas e em todas as categorias de estímulos. Este grupo caracteriza-se por apresentar sérias dificuldades em leitura e escrita de palavras isoladas, com comprometimento no uso de ambas as rotas de leitura e escrita de palavras. Metade destas crianças provinha da escola 2 e outra metade da escola 5.

Em resumo, as crianças com dificuldades de leitura e escrita provinham das escolas 1,2 e 5. Todas as crianças das escolas 3 e 4 eram leitoras/escritoras acima da média geral da amostra.

A Tabela 2 apresenta o desempenho de cada subgrupo nas tarefas de leitura e escrita de palavras isoladas. Na análise comparativa entre as médias da porcentagem de acertos nas tarefas de leitura e escrita de palavras, os três subgrupos formados pela análise de cluster diferiram significativamente entre si na tarefa de leitura de palavras isoladas $(\mathrm{F}(2 ; 107)=$ $109,09 ; \mathrm{p}<0,01)$, na leitura de palavras regulares ( $\mathrm{F}(2 ; 107)$ $=154,84 ; \mathrm{p}<0,01)$, irregulares $(\mathrm{F}(2 ; 107)=50,02 ; \mathrm{p}<0,01)$, pseudopalavras $(\mathrm{F}(2 ; 107)=61,06 ; \mathrm{p}<0,01)$ e no total da escrita de palavras isoladas $(\mathrm{F}(2 ; 104)=63,72 ; \mathrm{p}<0,01)$. Em todas estas categorias, o grupo DE apresentou os mais altos escores, enquanto que o grupo DMB, os mais baixos. Quando analisadas separadamente, as categorias de estímulos na escrita, o grupo com desempenho elevado em leitura e escrita (grupo DE) apresentou desempenho estatisticamente superior ao dos outros dois grupos, que não diferiram entre si, na escrita de palavras regulares $(\mathrm{F}(2 ; 104)=58,08$; $\mathrm{p}<0,01)$, irregulares $(\mathrm{F}(2 ; 104)=24,86 ; \mathrm{p}<0,01)$, regra $(\mathrm{F}$ $(2 ; 104)=30,09 ; \mathrm{p}<0,01)$ e de pseudopalavras $(\mathrm{F}(2 ; 104)=$ $46,98 ; \mathrm{p}<0,01)$. 
Tabela 2

Média e desvio-padrão (DP) da porcentagem de acertos na leitura e escrita de palavras isoladas, por grupo proveniente da análise de cluster

\begin{tabular}{|c|c|c|c|c|c|c|}
\hline & \multicolumn{2}{|c|}{$\underset{(n=95)}{\operatorname{grupo} D E}$} & \multicolumn{2}{|c|}{$\begin{array}{c}\text { grupo DB } \\
(\mathrm{n}=11)\end{array}$} & \multicolumn{2}{|c|}{$\begin{array}{c}\text { grupo DMB } \\
(n=4)\end{array}$} \\
\hline & Média & DP & Média & DP & Média & DP \\
\hline Leitura de palavras isoladas & $81,55 \mathrm{a}$ & 11,2 & $56,38 \mathrm{~b}$ & 8,4 & $7,4 \mathrm{c}$ & 8,7 \\
\hline Regulares & $92,42 \mathrm{a}$ & 10,36 & $65,0 \mathrm{~b}$ & 8,66 & $8,75 \mathrm{c}$ & 11,81 \\
\hline Irregulares & $71,62 \mathrm{a}$ & 16,51 & $38,18 b$ & 15,7 & $5,0 \mathrm{c}$ & 7,07 \\
\hline Pseudopalavras & $80,82 \mathrm{a}$ & 13,51 & $66,36 \mathrm{~b}$ & 15,82 & $6,25 c$ & 7,5 \\
\hline Escrita de palavras isoladas & $66,36 \mathrm{a}$ & 12,42 & $33,41 b$ & 7,69 & $16,25 \mathrm{c}$ & 17,38 \\
\hline Regulares & $92,39 a$ & 13,16 & $53,03 \mathrm{~b}$ & 23,36 & $33,33 b$ & 30,43 \\
\hline Irregulares & $46,47 \mathrm{a}$ & 16,05 & $21,08 b$ & 9,86 & $6,25 b$ & 7,22 \\
\hline Regras & $77,99 \mathrm{a}$ & 18,19 & $46,59 b$ & 15,9 & $21,87 b$ & 29,54 \\
\hline Pseudopalavras & $73,91 \mathrm{a}$ & 17,35 & $30,91 \mathrm{~b}$ & 17 & $17,5 b$ & 20,61 \\
\hline
\end{tabular}

Legenda: Grupo DE = Desempenho elevado; Grupo DB = Desempenho baixo;

Grupo DMB = Desempenho muito baixo.

a, b, c = médias seguidas de letras iguais não diferem significativamente ao nível de $5 \%$, entre os grupos.

\section{Estudo comparativo do desempenho em leitura/escrita entre os grupos de cada escola}

Os resultados do estudo comparativo do desempenho em leitura e escrita de palavras entre as crianças de cada escola são apresentados na Tabela 3. Analisando-se os escores totais na leitura e escrita de palavras isoladas, nota-se que alunos das escolas 3 e 4 apresentam médias de acertos superiores às dos alunos das outras escolas (lembrando que todos eles estavam também integrando o grupo com desempenho elevado em leitura/escrita pela análise de cluster).

$\mathrm{Na}$ comparação de médias entre grupos, segundo a variável escola (Teste One-Way Anova), verificou-se que, na leitura, as diferenças de desempenho não foram estatisticamente significativas. Porém, na escrita houve diferenças estatisticamente significativas entre os escores dos alunos de escolas diferentes. O desempenho das crianças da escola 3 no total da tarefa de escrita de palavras isoladas foi significativamente superior $(\mathrm{F}(4 ; 102)=3,1 ; \mathrm{p}<0,05)$ ao das crianças das escolas 1, 2 e 5. Estudantes da escola 3 também foram superiores àqueles das escolas 1 e 5 na escrita de palavras irregulares $(\mathrm{F}(4 ; 102)=5,01 ; \mathrm{p}<0,01)$. $\mathrm{Na}$ escrita de pseudopalavras também foram encontradas diferenças significativas $(F(4 ; 102)=4,51 ; p<0,01)$. Nessa categoria de estímulos, o desempenho das crianças da escola 1 foi inferior ao obtido pelas crianças das escolas 3 e 4 . Os estudantes da escola 3 também foram superiores aos da escola 5 na escrita de pseudopalavras.

Estes dados demonstram que a escola 3 se destacou pelos altos desempenhos dos alunos na tarefa de escrita. Alunos da escola 5, apesar de terem sido avaliados no final do ano letivo, apresentaram desempenho significativamente inferior ao das crianças das outras escolas em algumas categorias de estímulo da tarefa de escrita.

Tabela 3

Desempenho da amostra (média \pm desvio-padrão), em termos de porcentagem de acertos nas tarefas de leitura e de escrita de palavras isoladas, por escola

\begin{tabular}{lccccc}
\hline & Escola 1 & Escola 2 & Escola 3 & Escola 4 & Escola 5 \\
\hline Leitura de palavras isoladas & $74,44 \mathrm{a} \pm 15,46$ & $72,72 \mathrm{a} \pm 26,36$ & $82,99 \mathrm{a} \pm 10,34$ & $82,18 \mathrm{a} \pm 11,6$ & $70,97 \mathrm{a} \pm 22,54$ \\
Regulares & $85,4 \mathrm{a} \pm 16,38$ & $80,68 \mathrm{a} \pm 28,71$ & $94,52 \mathrm{a} \pm 8,05$ & $91,58 \mathrm{a} \pm 9,58$ & $82,39 \mathrm{a} \pm 25,22$ \\
Irregulares & $59,51 \mathrm{a} \pm 23,71$ & $62,8 \mathrm{a} \pm 28,5$ & $71,43 \mathrm{a} \pm 17,11$ & $76,05 \mathrm{a} \pm 15,14$ & $62,17 \mathrm{a} \pm 21,26$ \\
Pseudopalavra & $78,8 \mathrm{a} \pm 13,09$ & $74,54 \mathrm{a} \pm 27,42$ & $82,62 \mathrm{a} \pm 11,47$ & $78,68 \mathrm{a} \pm 15,08$ & $69,24 \mathrm{a} \pm 24,81$ \\
Escrita de palavras isoladas & $55,11 \mathrm{a} \pm 16,3$ & $60,11 \mathrm{a} \pm 20,85$ & $69,17 \mathrm{~b} \pm 14,06$ & $67,78 \mathrm{ab} \pm 16,31$ & $55,43 \mathrm{a} \pm 18,4$ \\
Regulares & $88,42 \mathrm{a} \pm 16,21$ & $84,85 \mathrm{a} \pm 26,18$ & $90,47 \mathrm{a} \pm 15,43$ & $86,11 \mathrm{a} \pm 26,35$ & $81,16 \mathrm{a} \pm 24,26$ \\
Irregulares & $35,88 \mathrm{a} \pm 17,99$ & $40,91 \mathrm{ab} \pm 18,37$ & $51,79 \mathrm{~b} \pm 16,67$ & $51,74 \mathrm{ab} \pm 17,12$ & $34,26 \mathrm{a} \pm 15,97$ \\
Regras & $67,93 \mathrm{a} \pm 18,0$ & $74,43 \mathrm{a} \pm 26,01$ & $79,17 \mathrm{a} \pm 16,92$ & $74,3 \mathrm{a} \pm 25,89$ & $68,48 \mathrm{a} \pm 26,35$ \\
Pseudopalavra & $55,22 \mathrm{a} \pm 24,47$ & $64,54 \mathrm{abc} \pm 27,73$ & $79,05 \mathrm{bc} \pm 18,41$ & $78,33 \mathrm{bc} \pm 16,89$ & $63,04 \mathrm{ac} \pm 21,41$ \\
\hline
\end{tabular}

Legenda: a, b, c = médias seguidas de letras iguais não diferem significativamente ao nível de $5 \%$, entre as escolas. 
A Figura 1 apresenta os gráficos da distribuição dos escores em leitura de palavras isoladas e de escrita de palavras isoladas, respectivamente, da amostra de cada escola.

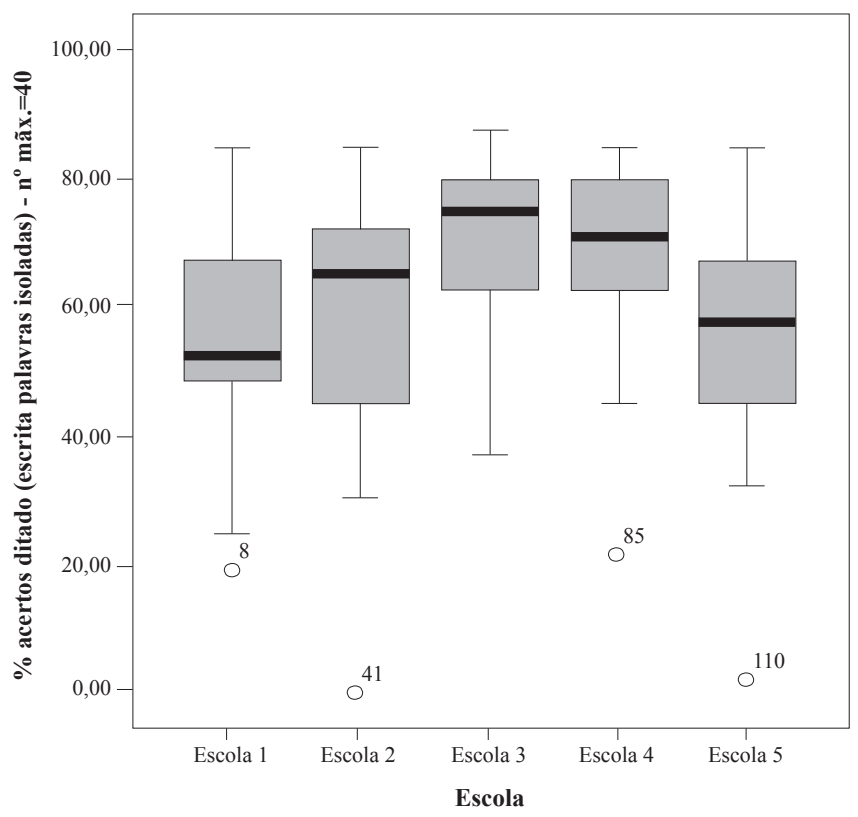

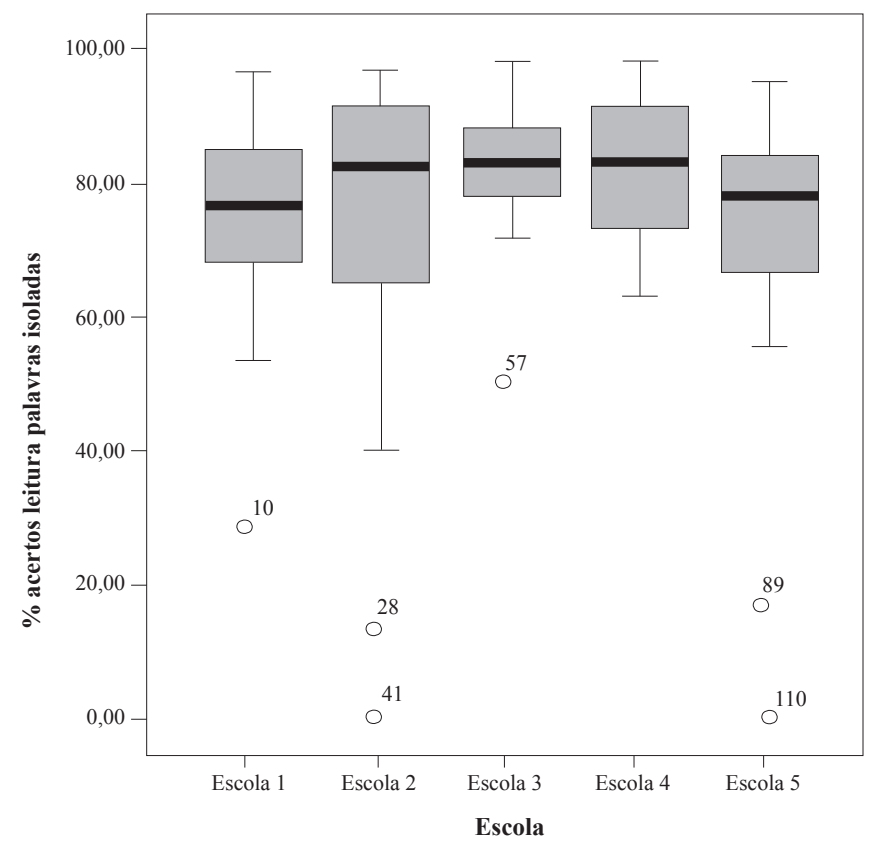

Figura 1. Distribuição dos escores (\% de acertos) na leitura de palavras isoladas (A) e na escrita de palavras isoladas (B), por escola.

No questionário de compreensão de leitura textual, como mostra a Tabela 4, as crianças da escola 3 apresentaram médias de acertos superiores às das demais escolas. Na comparação de médias entre grupos, segundo a variável escola (Teste One-Way Anova), foi encontrada diferença estatisticamente significativa $(\mathrm{F}(4 ; 104)=3,58$; $\mathrm{p}<0,01)$ entre os desempenhos dos alunos da escola 3 e da escola 5.

Tabela 4

Desempenho da amostra (média + desvio-padrão), em termos de porcentagem de acertos, no questionário de compreensão de leitura textual, por escola

\begin{tabular}{ccccc}
\hline Escola 1 & Escola 2 & Escola 3 & Escola 4 & Escola 5 \\
\hline $66,67 \pm 25,31$ & $58,18 \pm 33,61$ & $79,52 * \pm 19,1$ & $69,47 \pm 22,97$ & $53,04 * \pm 22,84$ \\
\hline
\end{tabular}

Legenda: * = médias diferem significativamente ao nível de $1 \%$.

\section{Discussão}

Os resultados da análise de cluster evidenciaram diferenças nas habilidades de leitura e de escrita nas crianças de segunda série de escolas públicas estaduais. Foram encontrados três grupos de crianças distintos, especialmente na leitura. Na escrita, os dois grupos com desempenho mais baixo pouco se diferenciaram, exceto quando considerado o escore total na tarefa. Segundo esta análise, foram encontrados que $13,64 \%(n=15)$ da amostra deste estudo apresenta algum tipo de dificuldade de leitura e/ou de escrita. Estas crianças provinham das escolas 1, 2 e 5. Esta proporção vai ao encontro de algumas estatísticas encontradas na literatura, como da Associação Brasileira de Dislexia [ABD] (2000), que a ocorrência de dislexia de desenvolvimento estaria em torno de $10-15 \%$ da população geral. Na literatura internacional, consta de 5 a $10 \%$ das crianças em idade escolar (Habib, 2000), o que reforça a evidência de que nem todos os problemas de leitura enquadram-se na definição de dislexias de desenvolvimento.

Uma questão a ser salientada é a coerência no uso das rotas de leitura e de escrita em cada grupo. No grupo com desempenho elevado, por exemplo, houve indícios de precisão no uso de ambas as rotas, especialmente na leitura, com 
predominância da rota fonológica (evidenciada pelo desempenho na leitura/escrita de pseudopalavras). A evidência do uso da rota lexical é baseada na capacidade de ler/escrever palavras irregulares. No grupo intermediário, com desempenho baixo em leitura e escrita, ambas as rotas estavam deficitárias, especialmente a lexical (escores na leitura/escrita de palavras irregulares). Portanto, a grande maioria das crianças (grupo com desempenho elevado) usava ambas as rotas de leitura e escrita de palavras.

O pequeno grupo denominado "desempenho muito baixo em leitura e escrita" apresentava sérias dificuldades de leitura e escrita, caracterizadas por prejuízos no desenvolvimento de ambas as rotas. Estas são percepções de análise de grupo, que obscurecem a variabilidade. Para confirmar se estas características são gerais, são necessárias análises individualizadas dos casos.

Nos grupos encontrados, exceto no último, em que ambas as rotas eram deficitárias, a rota fonológica parecia mais utilizada, tanto na leitura quanto na escrita. Nos estudos de Salles e Parente (2002a), foi encontrado um grupo de leitores preferencialmente lexicais, mas a amostra era constituída de crianças de segunda e terceira séries. Estas últimas, provavelmente, têm um léxico ortográfico mais amplo do que as primeiras, possibilitando a identificação precisa das palavras irregulares. Além disso, a amostra de Salles e Parente (2002a) era de escola particular.

Salles e Parente (2006) realizaram estudos de casos com os perfis extremos da mesma amostra utilizada no presente estudo (14 crianças com dificuldades de leitura e escrita e 15 crianças competentes em leitura e escrita) e encontraram dissociações duplas na leitura (os leitores preferencialmente fonológicos e os preferencialmente lexicais) e simples na escrita (escritores preferencialmente fonológicos) nas crianças de $2^{a}$ série com dificuldade de leitura e escrita. Além disso, houve casos em que ambas as rotas estavam deficitárias. Os casos de $2^{\mathrm{a}}$ série considerados competentes em leitura e escrita evidenciaram uso preciso de ambas as rotas de leitura, mas foi possível encontrar escritores preferencialmente lexicais e escritores preferencialmente fonológicos na escrita.

Salles e Parente (2008) analisaram as crianças de $2^{\mathrm{a}}$ série da mesma amostra utilizada no presente estudo, enquadradas no grupo com dificuldade de leitura e escrita $(n=14)$, e constataram variabilidade no perfil neuropsicológico, com dissociações entre as funções verbais e não-verbais. Cerca da metade destes casos apresentou baixo desempenho em consciência fonológica, memória verbal, linguagem oral e velocidade de processamento. A outra metade foi semelhante ao grupo competente de mesma série e idade.

Considerando o segundo objetivo deste estudo, o fator escola também mostrou relacionar-se às diferenças de desempenho em leitura e escrita das crianças. Um dos problemas quando se analisam aprendizagens escolares é que o desempenho da criança depende do tempo em que a análise é feita, ou seja, o período do ano letivo. A coleta de dados deste estudo iniciou em julho e foi finalizada em outubro.
Teoricamente, poderia ser esperada uma progressiva elevação das médias de desempenho em leitura e escrita entre os alunos das escolas 1 a 5 , visto que as últimas avaliadas estavam com mais tempo de escolarização do que as primeiras.

No estudo, apesar de ter havido variabilidade nos escores médios das crianças de cada escola na leitura de palavras isoladas, as diferenças não foram significativas. Certamente a variabilidade interna de cada classe escolar foi ainda maior, como mostrou a análise de cluster. Por outro lado, o desempenho na escrita de palavras isoladas foi heterogêneo entre escolas. Alunos da Escola 3, em média, foram superiores aos demais. No questionário de compreensão de leitura textual, novamente alunos da Escola 3 se destacaram.

Houve ampla variabilidade de desempenhos em leitura e escrita na amostra, mais expressiva na escrita. As Escolas 1 e 2 eram as únicas que atendiam também uma população de classe média, por estarem localizadas em áreas mais centrais da cidade.

Uma suposição para a maior heterogeneidade da escrita de palavras em relação à leitura de palavras é que o ensino da leitura seja mais homogêneo entre as escolas, comparado à ênfase na ortografia. Em muitas escolas, o ensino na segunda série enfatiza mais a produção de textos do que as regras de ortografia. Os Parâmetros Curriculares Nacionais (Ministério da Educação, 1997) mostram maior ênfase na produção de textos escritos coesos e coerentes em detrimento de aspectos ortográficos. Outra questão, já salientada na introdução, são as demandas de cada processo, compreensivo ou receptivo (leitura) e expressivo ou produtivo (escrita), além do maior número de irregularidade na língua para a escrita, comparado à leitura.

Como apontado no método, sob a denominação de fator escola há uma série de outros fatores subjacentes, como recursos físicos e humanos da escola, características do professor, qualidade e intensidade da instrução/ensino, relacionamentos professor-aluno e professor-pais, projeto político-pedagógico da escola, entre outros. Em termos de abordagem pedagógica, pelas falas das professoras foi possível inferir que todas usavam uma abordagem mista no ensino da leitura e escrita, estimulando a relação oralidade-escrita, e trabalhando com unidades maiores, como a palavra, a frase e o texto.

Além desses fatores contextuais relacionados à escola, os relacionados aos contextos familiares podem estar contribuindo para algumas diferenças de desempenho entre os alunos. Estudando crianças francesas, Leybaert e cols. (1997) encontraram que as variáveis socioeconômicas, como idade, sexo, nível de escolaridade dos pais, posição em relação aos irmãos e hábito familiar de contar histórias, explicaram cerca de $13 \%$ da variância dos escores em leitura e escrita ao fim do $2^{\circ}$ ano primário. O fator escola também teve um impacto substancial nas habilidades de leitura e escrita das crianças ao longo do $1^{\circ}$ e do $2^{\circ}$ anos primários, explicando $23,7 \%$ da variância, independente das diferenças socioeconômicas e das características cognitivas e linguísticas das crianças. 
Conclui-se que a amostra é heterogênea nas habilidades de leitura e escrita de palavras. Além das diferenças entre as crianças evidenciadas pela análise de cluster, houve diferenças de desempenho entre as crianças de escolas diferentes, mesmo que todas públicas e estaduais, na escrita de palavras e compreensão de leitura textual.

Pela análise de variabilidade nas habilidades de leitura e escrita (análise de cluster), foram encontrados claramente três subgrupos de crianças, que se diferenciam especialmente pelas habilidades de leitura, em todas as categorias de estímulos. Quando a comparação é feita pela variável escola, as habilidades de leitura parecem ser mais homogêneas entre crianças de diferentes escolas. O que realmente as difere são as habilidades de escrita de palavras/pseudopalavras. Desta forma, pode-se inferir que em cada turma de segunda série avaliada, há uma mescla de crianças competentes em leitura e aquelas que apresentam mais dificuldade. Porém, em termos de escrita, há nítidas diferenças de desempenho, conforme a escola frequentada.

A questão da maior variabilidade entre amostras de diferentes escolas na escrita de palavras, comparado ao processo de leitura de palavras, expõe duas reflexões pertinentes: uma voltada para o ensino destas habilidades (as atenções dadas em sala de aula para o ensino da leitura e para o ensino da escrita ortográfica), e outra inerente ao próprio sistema alfabético de escrita do português brasileiro (maiores irregulares no sistema de escrita de palavras). Esta variabilidade impõe dificuldades à confecção de tabelas normativas de desempenho esperado para cada série escolar. Desta forma, tanto o professor, que ensina, quanto o clínico que reabilita, precisam estar cientes das tendências (preferências) de estratégias de leitura e escrita que as crianças com desenvolvimento típico e aquelas com dificuldades nestas habilidades apresentam. Para esta análise, as avaliações precisam necessariamente partir de um modelo de processos cognitivos de desenvolvimento de leitura e escrita.

O presente estudo pretende evidenciar tal variabilidade, levantando possíveis fatores subjacentes, já que o método não permite inferências explicativas. Entre os fatores mais relevantes estão as características da escola, da família e do aluno (Oliveira, Boruchovitch, \& Santos, 2008). Resta aos clínicos, pesquisadores, professores e pais estarem cientes da complexidade de questões envolvidas no aprendizado bem sucedido da leitura e da escrita e, com isso, ficarem atentos a possíveis obstáculos a esse desenvolvimento.

\section{Referências}

Associação Brasileira de Dislexia. (2000). Dislexia: Cérebro, cognição e aprendizagem. São Paulo: Frôntis Editorial.

Carvalho, A. M. P. (2000). Baixo rendimento escolar: Uma visão a partir do professor. In C. A. R. Funayama (Org.), Problemas de aprendizagem: Enfoque multidisciplinar (pp. 115-146). Campinas, SP: Alínea.
Coppens, P., Parente, M. A. M. P., \& Lecours, A. R. (1998). Aphasia in Illiterate individuals. In P. Coppens, Y. Lebrun, \& A. Basso (Org.), Aphasia in atypical populations (pp. 175-202). London: Lawrence Erlbaum Associates Publishers.

Coltheart, M., Rastle, K., Perry, C., Langdon, R., \& Ziegler, T. (2001). DRC: Dual-route cascaded model of visual word recognition and reading aloud. Psychological Review, 108, 204-256.

DalVesco, A., Mattos, D., Benincá, C., \& Tarasconi, C. (1998). Correlação entre WISC e rendimento escolar na escola pública e na escola particular. Psicologia: Reflexão e Critica, 11, 481-495.

Ellis, A. W., \& Young, A. W. (1988). Human Cognitive Neuropsychology. London: Lawrence Erlbaum Associates.

Ferreira, S. P. A., \& Dias, M. G. B. B. (2002). Compreensão de leitura: Estratégias de tomar notas e da imagem mental. Psicologia: Teoria e Pesquisa, 18, 51-62.

Freitas, L. (1989). A produção de ignorância na escola: Uma análise crítica do ensino da língua escrita na sala de aula. São Paulo: Cortez.

Frith, U. (1997). Brian and Behaviour in Dyslexia. In C. Hulme \& M. J. Snowling (Eds.), Dyslexia: Biology, cognition and Intervention (pp. 1-19). London: Whurr.

Gardinal, E. C., \& Marturano, E. M. (2007). Meninos e meninas na Educação Infantil: Associação entre comportamento e desempenho. Psicologia em Estudo, 12, 541-551.

Habib, M. (2000). Bases neurológicas dos comportamentos. Lisboa: Climepsi Editores.

Johnson, R.A., \& Wichern, D. W. (1998). Applied multivariate statistical analysis. New Jersey: Prentice Hall.

Kleiman, A. (2001). Leitura: Ensino e pesquisa. Campinas, SP: Pontes.

Leybaert, J., Alégria, J., Deltour, J., \& Skinkel, R. (1997). Aprender a ler: O papel da linguagem, da consciência fonológica e da escola. In J. Grégoire \& B. Piérart (Orgs.), Avaliação dos problemas de leitura: Os novos modelos teóricos e suas implicações diagnósticas (pp. 143-166). Porto Alegre: Artes Médicas.

Silva, M. E. L., \& Spinillo, A. G. (1998). Uma análise comparativa da escrita de histórias pelos alunos de escolas públicas e particulares. Revista Brasileira de Estudos Pedagógicos, 79(193), 5-16.

Loureiro, S. R., Marturano, E. M., Linhares, M. B. M., Machado, V. L. S., \& Silva, R. A. (1994). Crianças com queixa de dificuldade escolar: Avaliação psicológica através de técnica gráfica. Arquivos Brasileiros de Psicologia Aplicada, 46, 161-182.

Malloy-Diniz, L. F., Wellington B. L., Moraes, P. H. P., Correa, H., Bechara, A., \& Fuentes, D. (2008). Versão em português do Iowa Gambling Test: Adaptação transcultural e validade discriminante. Revista Brasileira de Psiquiatria, 30, 144-148. 
Marturano, E. M. (1999). Recursos no ambiente familiar e dificuldades de aprendizagem na escola. Psicologia: Teoria e Pesquisa, 15, 153-162.

Medeiros, P. C., Loureiro, S. R., Linhares, M. B. M., \& Marturano, E. M. (2000). A Auto-eficácia e os aspectos comportamentais de crianças com dificuldade de aprendizagem. Psicologia: Reflexão e Critica, 13, 327-336.

Medeiros, P. C., Loureiro, S. R., Linhares, M. B. M., \& Marturano, E. M. (2003). O senso de e o comportamento orientado para aprendizagem em crianças com queixa de dificuldade de aprendizagem. Estudos de Psicologia (Natal), 8, 93-105.

Ministério daEducação. Secretaria de EducaçãoFundamental. (1997). Parâmetros Curriculares Nacionais: Lingua portuguesa. Brasília: Ministério da Educação.

Nogueira, G. J., Castro, A., Naveira, L., Nogueira-Antuñano, F., Natinzon, A., Gigli, S.L., Grossi, M.C., Frugone, M., Leofanti, H., \& Marchesi, M. (2005). Evaluación de las funciones cerebrales superiores en niños de $1^{\circ} \mathrm{E} 7^{\circ}$ grado pertenecientes a dos grupos socioeconómicos diferentes. Revista de Neurologia, 40, 397-406.

Oliveira, E. T. A., \& Wescher, S. M. (2002). Variáveis que afetam a aprendizagem: Percepção de alunos de licenciatura e professores. Psicologia Escolar $e$ Educacional, 6, 133-139.

Oliveira, K. L. Boruchovitch, E., \& Santos, A. A. A. (2008). Leitura e desempenho escolar em português e matemática no ensino fundamental. Paidéia (Ribeirão Preto), 18, 531-540.

Pagliuso, L., \& Pasian, S. R. (2007). As figures complexas de Rey: Normas preliminares com crianças de 9 e 10 anos. Psico, 38, 148-156.

Pennington, B. F. (1997). Diagnóstico de distúrbios de aprendizagem: Um referencial neuropsicológico. São Paulo: Pioneira.

Pinheiro, A. M. V. (1996). Contagem de frequência de ocorrência de palavras expostas a crianças na faixa de pré-escola e séries iniciais. Software produzido pela Associação Brasileira de Dislexia - ABD.

Pinheiro, A. M. V. (2001). Heterogeneidade entre leitores julgados competentes pelas professoras. Psicologia: Reflexão e Crítica, 14, 537-551.

Rocha, R. (1997). A Coisa. In C. S. Carvalho \& M. D. Baraldi (Orgs.), Construindo a escrita: Leitura e interpretação de textos (pp. 86-95). São Paulo: Ática.

Salles, J. F., \& Parente, M. A. M. P. (2002a). Relação entre os processos cognitivos envolvidos na leitura de palavras e as habilidades de consciência fonológica em escolares. Pró-Fono Revista de Atualização Científica, 14, 141286.

Salles, J. F., \& Parente, M. A. M. P. (2002b). Processos cognitivos na leitura de palavras em crianças: Relações com compreensão e tempo de leitura. Psicologia: Reflexão e Crítica, 15, 321-331.
Salles, J. F., \& Parente, M. A. M. P. (2006). Heterogeneidade nas estratégias de leitura/escrita em crianças com dificuldades de leitura e escrita. Psico, 37, 83-90.

Salles, J. F., \& Parente, M. A. M. P. (2007a). Avaliação da leitura e escrita de palavras em crianças de $2^{\mathrm{a}}$ série: Abordagem neuropsicológica cognitiva. Psicologia: Reflexão e Crítica, 20, 218-226.

Salles, J. F., Parente, M. A. M. P. (2007b). Relação entre desempenho infantil em linguagem escrita e percepção do professor. Cadernos de Pesquisa, 37, 687-709.

Salles, J. F., \& Parente, M. A. M. P. (2008). Variabilidade no desempenho em tarefas neuropsicológicas entre crianças de $2^{\mathrm{a}}$ série com dificuldades de leitura e escrita. Arquivos Brasileiros de Psicologia, 60(1), 32-44.

Sousa, E. O. \& Maluf, M. R. (2005). Habilidades de leitura e de escrita no início da escolarização. Psicologia da educação, 19, 55-72.

Sternberg, R. J., \& Grigorenko, E. L. (2003). Crianças Rotuladas: O que é necessário saber sobre as dificuldades de aprendizagem. Porto Alegre: Artes Médicas.

Tasca, M. (1990). A linguagem dos materiais de alfabetização. In M. Tasca \& J. M. Poersch (Orgs.), Suportes linguísticos para a alfabetização (pp. 119-134). Porto Alegre: Sagra.

Tasca, M. (2002). Interferência da língua falada na escrita das séries iniciais: O papel de fatores linguísticos e sociais. Porto Alegre: EDIPUCRS.

Witter, G. P. (1996). Fatores socioculturais e leitura: Estudo da produção arrolada no ASIRR (1989/1994). Estudos de Psicologia, 13, 49-56.

Yavas, F., \& Haase, V. G. (1988). Consciência fonêmica em crianças na fase de alfabetização. Letras de Hoje, 23(4): 31-55.

Jerusa Fumagalli de Salles é Professora Adjunta do Instituto de Psicologia, Departamento de Psicologia do Desenvolvimento e da Personalidade, Programa de Pósgraduação em Psicologia, da Universidade Federal do Rio Grande do Sul-UFRGS.

Maria Alice de Mattos Pimenta Parente é Professora Adjunta do Instituto de Psicologia, Departamento de Psicologia do Desenvolvimento e da Personalidade, Programa de Pósgraduação em Psicologia, da Universidade Federal do Rio Grande do Sul-UFRGS.

Lia Beatriz de Lucca Freitas é Professora Adjunta do Instituto de Psicologia, Departamento de Psicologia do Desenvolvimento e da Personalidade, Programa de Pósgraduação em Psicologia, da Universidade Federal do Rio Grande do Sul-UFRGS. 